\title{
Is it possible to define a best practice standard for coercive treatment in psychiatry? Norman Sartorius
}

\author{
Address: 14 chemin Colladon, 1209 Geneva, Switzerland \\ from WPA Thematic Conference. Coercive Treatment in Psychiatry: A Comprehensive Review \\ Dresden, Germany. 6-8 June 2007 \\ Published: 19 December 2007 \\ BMC Psychiatry 2007, 7(Suppl I):S9 doi:I0.1 186/I47I-244X-7-SI-S9
}

This abstract is available from: http://www.biomedcentral.com//47I-244X/7/SI/S9

C 2007 Sartorius; licensee BioMed Central Ltd.

Practice standards are rules for the behavior of health personnel - any deviation from these rules is punishable and their application is likely to be enforced. They have to be based on evidence about health staff behavior that is most useful for effective and humane care. Such evidence exists only in part and even when it is available it is related to a local rather than global context. The definition of universal rules for best practice (standards) is therefore not possible at this point in time.

Guidelines for best practice would be based on the best of evidence and experience about (in the local situation) useful behaviors. Guidelines allow users to deviate from them in the light of the situations in which patients live and health staff work. They are therefore more useful than strict standards of best practice at the current stage of our knowledge. Guidelines should be used in conjunction with general standards of medical practice that cover the protection of the patients from abuse and insist on providing help in situations of danger to life. Both guidelines and standards should be based on ethical principles that should govern medicine as well as psychiatry. 